
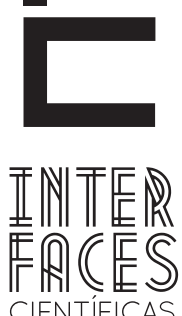

HUMANAS E SOCIAIS

ISSN IMPRESSO 2316-3348

E-ISSN 2316-3801

DOI - 10.17564/2316-3801.2018v6n3p155-164

\title{
A QUESTÃO DA SUSTENTABILIDADE E A SUA INSERÇÃO NO CONTEXTO CORPORATIVO
}

THE ISSUE OF SUSTAINABILITY AND ITS INTEGRATION INTO THE CORPORATIVE CONTEXT

LA CUESTIÓN DE LA SUSTENTABILIDAD Y SU INSERCIÓN EN EL CONTEXTO CORPORATIVO

Rogério dos Santos Lima

Marcos dos Santos ${ }^{3}$
Gustavo Benttenmüller Medeiros Pereira²

Renato Santiago Quintal ${ }^{4}$

\section{RESUMO}

0 objetivo do presente artigo é sistematizar argumentos afetos à temática acerca da sustentabilidade, bem como a sua interface com o segmento empresarial. Sob a perspectiva metodológica a presente pesquisa classifica-se como qualitativa, não experimental e bibliográfica. Nesse contexto, certamente a questão ambiental gera impactos na sociedade como um todo, independente de nível econômico e social, tornando-se um elemento chave para a reformulação dos valores em vigor na sociedade, produzindo novas formas de ação em todas as práticas produtivas. A despeito de algumas empresas adotarem estratégias sustentáveis em seus processos produtivos, muitas ainda não priorizam a sustentabilidade e não sabem como agir de forma integrada ao negócio, adotam abordagens e projetos de forma pontual e desvinculada da estratégia da empresa. As ações de melhoria ambiental no processo produtivo podem estar relacionadas à redução de custo, melhoria de processos e diminuição de emissões e resíduos industriais, diferenciando o produto, com foco na competitividade. Nessas circunstâncias, faz-se necessário destacar que a transição de um modelo tradicional de gestão de produtos para um modelo com foco em sustentabilidade requer fundamentalmente 0 envolvimento direto da alta liderança e o estabelecimento de metas empresariais compatíveis com os objetivos de desenvolvimento sustentável.A relevância da presente pesquisa reside na sua contribuição à construção do conhecimento em sustentabilidade, em especial pela atualidade da matéria, a qual vem sendo discutida nos mais distintos fóruns.

\section{PALAVRAS-CHAVE}

Desenvolvimento Sustentável. Meio Ambiente. Gestão Ambiental. 


\section{ABSTRACT}

The purpose of this article is to systematize affections arguments about the theme of sustainability, as well as its interface with the business segment. Under the methodological perspective this research is classified as qualitative, not experimental and bibliographic research. In this context, certainly environmental issues has an impact on society as a whole, regardless of economic and social level, becoming a key element in reshaping the values in force in society, producing new forms of action in all productive practices. Despite some companies adopt sustainable strategies in their production processes, many still do not prioritize sustainability and do not know how to act in an integrated way to the business, adopt approaches and projects in a timely manner and disconnected from the company's strategy. The environmental improvement actions in the production process may be related to cost reduction, process improvement and reduction of emis- sions and industrial waste, differentiating the product, focusing on competitiveness. In these circumstances, it is necessary to emphasize that the transition from a traditional model of product management for a model with a focus on sustainability essentially requires the direct involvement of top management and the establishment of business goals compatible with sustainable development objectives. The relevance of this research lies in its contribution to the construction of knowledge on sustainability, particularly by today's matter, which has been discussed in widely different forums.

\section{KEYWORDS}

Sustainable development. Environment. Environmental management.

\section{RESUMEN}

El objetivo del presente artículo es sistematizar argumentos afectos a la temática sobre la sostenibilidad, así como su interfaz con el segmento empresarial. Bajo la perspectiva metodológica la presente investigación se clasifica como cualitativa, no experimental y bibliográfica. En este contexto, ciertamente la cuestión ambiental genera impactos en la sociedad como un todo, independiente de nivel económico y social, convirtiéndose en un elemento clave para la reformulación de los valores en vigor en la sociedad, produciendo nuevas formas de acción en todas las prácticas productivas. A pesar de que algunas empresas adoptan estrategias sostenibles en sus procesos productivos, muchas todavía no priorizan la sostenibilidad y no saben cómo actuar de forma integrada al negocio, adoptan enfoques y proyectos de forma puntual y desvinculada de la estrategia de la empresa. Las acciones de mejora ambiental en el proceso productivo pueden estar relacionadas con la reducción de costo, mejora de procesos y disminución de emisiones y residuos industriales, diferenciando el producto, con foco en la competitividad. En estas circunstancias, es necesario destacar que la transición de un modelo tradicional de gestión de productos a un modelo con foco en sostenibilidad requiere fundamentalmente la participación directa del alto liderazgo y el establecimiento de metas empresariales compatibles con los objetivos de desarrollo sostenible. La relevancia de la presente investigación reside en su contribución a la construcción del conocimiento en sustentabilidad, en especial por la actualidad de la materia, la cual viene siendo discutida en los más distintos foros.

\section{PALABRAS CLAVE}

Desarrollo sostenible; Medio ambiente; Gestión ambiental. 


\section{INTRODUÇ̃̃O}

0 atual modelo de crescimento econômico, os riscos e impactos das mudanças climáticas e a preeminente necessidade de focar em uma economia de baixo carbono trazem desafios para a sociedade como um todo com relação ao desenvolvimento sustentável.

As empresas, por meio de lideranças corporativas sensíveis às questões desustentabilidade, são fundamentais para conduzir novos processos que vão ao encontro dos dilemas do desenvolvimento sustentável, influenciando a demanda de mercado e estabelecendo novos padrões de consumo com foco em produtos e serviçosambientalmente corretos, socialmente justos e que continuam trazendo retornos financeiros para as empresas e seus acionistas.

Nesse contexto, o objetivo do presente artigo é sistematizar argumentos afetos à temática acerca da sustentabilidade, bem como a sua interface com o segmento empresarial. Sob a perspectiva metodológica a presente pesquisa classifica-se como qualitativa, não experimental e bibliográfica.

A relevância da presente pesquisareside na sua contribuição à construção do conhecimento em sustentabilidade, em especial pela atualidade da matéria, a qual vem sendo discutida nos mais distintos fóruns.

\section{REFERENCIAL TEÓRICO}

\subsection{DESENVOLVIMENTO SUSTENTÁVEL}

Desenvolvimento sustentável corresponde ao desenvolvimento que supre as demandas dopresente sem afetar a capacidade de as gerações vindouras satisfazerem assuas próprias necessidades (BRÜSEKE, 1995).

$O$ conceito do desenvolvimento sustentável foi introduzido com a publicação do Relatório Brundtland, pelas Nações Unidas, que o define como aquela modalidade de desenvolvimento que almeja a satisfação das necessidades atuais sem o comprometimento da habilidade das gerações vindouras em satisfazer as suas próprias necessidades (LEFF, 2008; YOSHIDA, 2009 apudMELLO, 2009).

Para Brüseke (1995), o conceito de desenvolvimento sustentável tem uma acepção fortemente positiva. Tanto o Banco Mundial, quanto a Organização para a Educação, a Ciência e a Cultura das Nações Unidas (UNESCO) e outras entidades internacionais utilizaram-no para delinear uma nova filosofia do desenvolvimentoque associa eficiência econômica a justiça social e prudência ecológica. Essetripé transformou-se em fórmula mágica, que não falta em nenhuma solicitação de recursos paraprojetos da natureza mais diversa no campo eco-sócio-econômico dos países em desenvolvimento. 0 conceito desenvolvimentosustentável evidencia uma alternativa às teorias e aos modelos tradicionais dodesenvolvimento, deterioradas numa série infinita de desapontamentos.

\subsection{TEORIA DOS STAKEHOLDERS}

A Teoria dos Stakeholders, proposta por Freeman (1984), pode explicar e guiar a estrutura e operação de uma empresa, sendo que a gestão eficiente dos stakeholders contribui com o sucesso do desempenho econômico empresarial. Essa teoria, sob a ótica da sustentabilidade, traz à luz a necessidade de as empresas pautarem suas decisões estratégicas por interesses econômicos de seus acionistas, assim como com os interesses dos demais stakeholders na perspectiva social e ambiental. Nesse sentido, o envolvimento de um número maior de stakeholders nas decisões e estratégias empresariais viabiliza a inovação.

Da Silveira, Yoshinagae Borba (2005) abordam de maneira crítica a teoria de equilíbrio dos interesses dos stakeholders,apresentando suas origens, conceitos, aspectospositivos e negativos, contrapondo-a com a teoria damaximização da riqueza dos acionistas e retratando uma abordagem unificadora propostapor Jensen (2001apud DA SILVEIRA; YOSHINAGA; BORBA, 2005). A análise destacou asfragilidades conceituais da teoria dos stakeholders. 


\subsection{ANÁLISE DO CICLO DE VIDA}

A ISO 14.040 trata de gestão ambiental, avaliação do ciclo de vida e princípios e estrutura. Nesse contexto, a Análise do Ciclo de Vida (ACV) é uma metodologia desenvolvida para avaliar os aspectos ambientais e os potenciais impactos de um produto, do berço ao túmulo, desde o acesso à matéria-prima, passando por seu processo de produção, até seu uso e descarte. Essa avaliação é feita com diversos stakeholders da empresa, envolvendo, principalmente, a cadeia de valor desta (ABNT, 2001).

Hinze outros autores(2006) afirmam que a ACV surgiu da necessidade de se estabelecer uma metodologia que tornasse mais compreensível a análise e a identificação dosimpactos ambientais em relação às atividades de uma empresa, incluindo seus produtos e processos. A partirdessa metodologia,é possível verificar que a prevenção à poluição se torna mais racional, econômica e efetivada que uma ação na direção dos efeitos gerados. Nesse contexto, um dos objetivos da ACV é formular uma sistemática confiável e que possa ser reproduzida a fimde identificar, em um conjunto de distintas atividades, aquela que terá menor impacto ambiental. Portanto, a ACV ultrapassa a visão focada apenas no processo produtivo, no tratamento e disposição dos dejetos produzidos durante a fabricação, para uma visão holística dos impactos ambientaisassociados a todas as fases do ciclo de vida.

\section{ASPECTOS METODOLÓGICOS}

Segundo a natureza dos dados, a presente pesquisa classifica-se como qualitativa. No que tange ao nível de controle das variáveis, a pesquisa enquadra-se como não experimental (GIL, 2010).

Quanto aos objetivos mais gerais, o presente estudo pode ser classificado como exploratório, uma vez que tem como propósito proporcionar maior familiaridade com o problema, com vistas a torná-lo mais explícito. Outrossim, reveste-se de um planejamento dotado de maior flexibilidade, uma vez que são rele- vantes as mais diversas facetas referentes ao objeto em análise (GIL, 2010).

0 trabalho também contemplou pesquisa bibliográfica. Foram consultados materiais impressos e em meio magnético, relacionados a livros, revistas, jornais, teses, dissertações e anais de eventos científicos (GIL, 2010). Nesse contexto, no que tange aos artigos científicos, os mesmos foram pesquisados nas seguintes bases acadêmicas: Scientific Electronic Library Online (SciELO); EBSCO; Red de Revistas Cientificas de America Latina y El Caribe, España y Portugal (REDALYC); Sistema Regional de Información en Línea para Revistas Científicas de América Latina, el Caribe, España y Portugal (LATINDEX); Scientific Periodicals Electronic Library (SPELL); Instituto Brasileiro de Informação em Ciência e Tecnologia (IBICT); Sumários de Revistas Brasileiras (Sumários.org); e Google Acadêmico. Por ocasião da pesquisa, foram empregados os seguintes descritores: sustentabilidade; desenvolvimento sustentável; meio ambiente; e gestão ambiental.

Ademais, a pesquisa pode ser classificada como um estudo de caso. Para Yin (2010, p. 39), o estudo de caso representa um procedimento de natureza empírica que "investiga um fenômeno contemporâneo em profundidade e em seu contexto de vida real", notadamente quando os limites entre fenômeno e contexto não se encontram perfeitamente delineados.

0 estudo em questão concebe a pesquisa qualitativa como técnica de pesquisa utilizada, a qual indica a forma pela qual será empreendida a análise de dados. Na pesquisa qualitativa, essencialmente, o pesquisador almeja levantar opiniões, as crenças, o significado das coisas nas palavras dos participantes da pesquisa. Existe interação com os indivíduos, sendo mantida a neutralidade. Não ocorrem generalizações; reveste-se de um procedimento exploratório, com a finalidade de perquirir conhecimentos acerca de uma questão, para a qual as informações acessíveis ainda são escassas (VIEIRA, 2009).

\section{ANÁLISE E DISCUSSÃO}

Cada vez mais a agenda ambiental das empresas incorpora o conceito de triple bottonline, consideran- 
do o equilíbrio, pelo qual as demandas dos stakeholders, ou partes interessadas, tornam-se a base de uma nova visão do capitalismo, das dimensões econômica, social e ambiental no desenvolvimento de soluções viáveis (ELKINGTON, 1998). Na visão de Almeida (2002), é necessário promover uma mudança de atitude por parte de todos, com o objetivo de acelerar a transição de um mundo baseado em um modelo esgotado de relações ambientais, econômicas e sociais para a nova era da sustentabilidade.

Veiga e Zatz (2008) complementam que conciliar crescimento econômico e conservação ambiental é um grande dilema, que se manifesta por meio de grandes desafios, incluindo a preservação da camada de ozônio, da biodiversidade, dos recursos naturais e do crescimento populacional. Abramovay (2012) argumenta que, no contexto de fomento da economia verde, políticas afirmativas de inclusão dos pobres ao trabalho, de transferência de renda a estes e políticas focadas em sustentabilidade são fundamentais em uma economia em que a ética e o respeito aos limites dos ecossistemas estão no centro das decisões.

No entanto, ainda há poucas empresas e lideranças corporativas que reconhecem a importância do fomento de uma economia verde e a necessidade de reinventar a dinâmica empresarial, a fim de esta considerar a sustentabilidade em suas estratégias de negócio.

Muitos executivos subestimam as oportunidades estratégicas nessa área, cumprindo apenas o que a legislação obriga, não considerando que as questões de sustentabilidade, no âmbito da estratégia corporativa, podem reduzir custos e riscos (HART; MILSTEIN, 2004). Nesse sentido, a sustentabilidade deve ser inserida em um contexto empresarial pautado em inovação e vantagens competitivas.

Para Kotler e Keller (2006), o aumento da expectativa e exigência dos clientes, das legislações e pressões por parte do governo e do interesse dos investidores em critérios de sustentabilidade são alguns dos principais motivos que levam as empresas a considerarem a sustentabilidade como parte integrante de suas estratégias corporativas.
Complementarmente, Porter e Linde (1995a) afirmam que a economia mundial está em transição. Para esses autores, é preciso relacionar competitividade com o meio ambiente, aumentar a eficiência dos produtos existentes ou a quantidade de produtos com mais valor agregado para os clientes. 0 novo paradigma da competitividade global requer a habilidade das empresas de se modernizarem rapidamente, considerando a rápida transformação tecnológica e o melhor desempenho ambiental. É preciso usar os recursos naturais, financeiros e humanos de forma eficiente.

De acordo com Nidumolu, Prahalad e Rangaswami (2009), a liderança e o talento são elementos essenciais para o desenvolvimento de um novo modelo de negócio pautado na contribuição para uma economia de baixo carbono, bem como para atender às diferentes necessidades de clientes e stakeholders. Os executivos devem questionar-se e empreender novas soluções com foco em inovação e sustentabilidade, para que o impacto de um novo produto ou processo possa estender-se para diversos mercados. Hart e Milstein (2004) afirmam que a sustentabilidade é baseada em crescimento econômico e pode ser importante fonte de vantagem competitiva e geração de valor para os acionistas e a comunidade como um todo.

Outro importante aspecto é a governança da sustentabilidade, tendo em vista as demandas de seus stakeholders. As empresas precisam se renovar e adaptarem suas práticas de governança corporativa com foco na sua competitividade e nas oportunidades de mercado, gerando riqueza e valor com critérios de sustentabilidade (BENITES; POLO, 2013).

De maneira geral, as empresas estão sendo desafiadas cada vez mais a responder às pressões globais e de seus stakeholders por práticas de gestão modernas com foco em sustentabilidade (CARDOSO et al., 2008). Para Conde (2013), os desafios empresariais na gestão da sustentabilidade devem dar importância também aos fatores humanos, como as populações tradicionais e urbanas, reféns de indústrias poluidoras, assim como às populações rurais pressionadas, cada vez mais, pelo agronegócio gerido de forma insustentável, acarretando impactos ao meio ambiente e às comunidades. 
Se, por um lado, a trajetória do desenvolvimento sustentável é complexa, por outro pode trazer oportunidades para as empresas. Marcovitch (2006) afirma que algumas empresas brasileiras apresentam sensibilidade estratégica e alinhamento com as novas demandas da sociedade. Nesse sentido, o autor destaca a importância do empreendedorismo sustentável em trazer soluções renovadoras a fim de contribuir para o equilíbrio econômico, ambiental e social.

É nesse contexto de empreendedorismo que o incentivo à inovação empresarial mostra-se fundamental para a criação de produtos sustentáveis. As soluções que vão ao encontro do desenvolvimento sustentável passam pela geração de inovações com relação aos processos produtivos e aos produtos, sem desconsiderar os impactos ambientais e sociais das novas tecnologias (DAROIT; NASCIMENTO, 2004).

Empresas dessa natureza e com grande visão de futuro já consideram as questões de sustentabilidade como oportunidade, redução de risco e fonte de vantagem competitiva. Segundo Porter e Linde (1995b), as empresas mais competitivas são aquelas que têm capacidade de melhorar e se reinventarem continuamente. Eles reconhecem, ainda, que a inovação com foco em produtos verdes traz benefícios para as empresas, incluindo redução de custo por atender às regulações ambientais, otimização nos processos produtivos e nos recursos e melhora na qualidade e desempenho dos produtos. Nesse sentido, muitas empresas consideram a inovação com foco em sustentabilidade um diferencial competitivo na definição de preços diferenciados para produtos verdes, bem como na exploração de novos mercados.

Maxwell e Van der Vorst (2003) definem o desenvolvimento de produtos sustentáveis como um processo de produção sustentável, considerando o ciclo de vida completo do produto, desde sua concepção até seu descarte. Nesse processo produtivo são considerados o equilíbrio entre a proteção ambiental, a equidade social e a prosperidade econômica, integrados aos requerimentos tradicionais de um produto, como qualidade, mercado, especificação técnica e preço.

0 resultado esperado é a integração dos benefícios do negócio com a redução dos impactos sociais e ambientais. De maneira semelhante, é possível dialogar com Abrantes (2009), que propõe um modelo teórico de Análise de Ciclo de Vida (ACV), abrangendo tanto os aspectos mercadológicos propostos por Kotler (1999) como os aspectos da produção e impacto ambiental. Nesse mesmo diapasão, Silva e Kulay (2006) argumentam sobre a demanda das organizações no gerenciamento de sua relação com o meio ambiente e sobre a importância da Análise do Ciclo de Vida (ACV) do ponto de vista da sustentabilidade, desde a obtenção dos recursos naturais até sua disposição final.

Os autores destacam que o transporte é incluído como uma etapa do ciclo de vida por ser uma atividade potencialmente geradora de impactos ambientais, que ocorre praticamente no ciclo de vida de todos os produtos. Para Hart e Milstein (2004), existe um movimento, por parte das empresas inovadoras, de expansão de seus sistemas de gestão do meio ambiente para a metodologia de ACV, com o intuito de ultrapassar as fronteiras da organização para o gerenciamento de produtos, considerando toda a sua cadeia produtiva de forma sustentável.

Têm-se como resultados desse processo a redução do impacto ambiental e risco, a possibilidade de redução de custo, a inovação no produto por meio de melhoria nos processos ou materiais, as melhores relações comunitárias, a legitimidade e a reputação da marca. Nesse aspecto, Smeraldi (2009) afirma que o aumento da produtividade dos recursos é um grande desafio de curto prazo para a sustentabilidade corporativa, pois inclui redução de desperdício, transformação de resíduos em matéria-prima, materiais alternativos, redução de energia e no transporte. Essas atividades são bastante importantes, já que contribuem para a melhoria do desempenho dos negócios, além de gerarem novos negócios sustentáveis.

Hart e Milstein (2004) destacam que a trajetória do crescimento de uma empresa, pautada pela sustentabilidade, deve ser baseada em uma estratégia que facilite a imaginação competitiva com base na criação de mapas comuns para os negócios de amanhã, considerando as necessidades de seus stakeholders por 
meio do seu engajamento. Desse modo, as lideranças terão uma diretriz em termos de prioridades organizacionais, desenvolvimento de tecnologia inovadora, alocação de recursos e planejamento de modelos de negócio, possibilitando, assim, o desenvolvimento de produtos sustentáveis.

Atualmente, as discussões sobre meio ambiente vêm se revestindo de crescente significância, passando a ser verificados especialmente sob a sua expressão em termos financeiros, habilmente retratados pelas ciências sociais aplicadas, especialmente a ciência econômica e a ciência contábil.

O sistema econômico determina dupla pressão sobre o meio ambiente, captando seus recursos - alguns indiscutivelmente esgotáveis - e despejando na natureza a cada instante os resíduos oriundos de ação humana. Nessas circunstâncias, a concepção do mito do desenvolvimento econômico, forjada por Celso Furtado, está associada com o fato de que o modelo da economia em expansão destrói e favorece a degradação em larga escala do meio ambiente, bem como conduz a ilusão de que, com o crescimento da economia, verifica-se o desenvolvimento (CAVALCANTI, 2002).

Maciel e outros autores (2010) e Santos e colaboradores (2001) afirmam que a contabilidade ambiental representa um instrumento responsável pelo auferimento dos resultados para as atividades das empresas conectadas ao meio ambiente, valendo como indício para reorientar políticas em favor de um desenvolvimento sustentável.

\section{CONSIDERAÇÕES FINAIS E CONCLUSÕES}

O objetivo do presente artigo foi sistematizar argumentos afetos à temática acerca da sustentabilidade, bem como a sua interface com o segmento empresarial.

É certo que a questão ambiental produz reflexos na sociedade como um todo, independente de nível econômico e social, tornando-se um elemento chave para estabelecer novas bases nos valores vigentes na sociedade, gerando novas formas de ação em todas as práticas produtivas.
Contudo, é possível perceber que a questão ambiental ainda não foi alçada ao protagonismo em organizações empresariais e em Instituições de Ensino Superior, a despeito da gradativa importância que a temática vem adquirindo com o transcurso do tempo.

A literatura especializada consultada encontra-se alicerçada especialmente nos seguintes autores: Freeman (1984), o qual propôs a Teoria dos Stakeholders; Nidumolu, Prahalad e Rangaswami (2009), autores que consideram que a liderança como fator crítico para o desenvolvimento de um novo modelo de negócio pautado na contribuição para uma economia de baixo carbono; Hart e Milstein (2004), para os quais empresas inovadoras expandem seus sistemas de gestão do meio ambiente para a metodologia de ACV, considerando toda a sua cadeia produtiva de forma sustentável e estabelecem uma visão de sustentabilidade, contemplando as necessidades de seus stakeholders.

A despeito de algumas empresas adotarem estratégias sustentáveis em seus processos produtivos, muitas ainda não priorizam a sustentabilidade e não sabem como agir de forma integrada ao negócio, adotam abordagens e projetos de forma pontual e desvinculada da estratégia da empresa. 0 foco muitas vezes é no resultado em curto prazo e em soluções imediatistas para a solução de problemas. Estas empresas, em geral, não possuem visão de sustentabilidade no negócio e não vislumbram oportunidades.

A despeito dos avanços observados nas últimas décadas, verifica-se que há um longo caminho a ser trilhado, haja vista que em pleno século XXI observam-se ações humanas responsáveis por grandes prejuízos ao meio ambiente e à coletividade que dele depende.

Em última análise, sob a ótica empresarial, as ações de melhoria ambiental no processo produtivo podem estar relacionadas à redução de custo, melhoria de processos e diminuição de emissões e resíduos industriais, diferenciando o produto, com foco na competitividade. Nessas circunstâncias, faz-se necessário destacar que a transição de um modelo tra- 
dicional de gestão de produtos para um modelo com foco em sustentabilidade requer, fundamentalmente, o envolvimento direto da alta liderança e o estabelecimento de metas empresariais compatíveis com os objetivos de desenvolvimento sustentável.

\section{REFERÊNCIAS}

ABRAMOVAY, R. Muito além da economia verde. São Paulo: Planeta Sustentável; Abril, 2012.

ABRANTES, J. Ciclo de vida de um produto: considerações mercadológicas da produção e de conservação do meio ambiente. In: ALIGLERI, L.; ALIGLERI, L.A.; KRUGLIANSKAS, I. Gestão socioambiental: responsabilidade e sustentabilidade do negócio. São Paulo: Atlas, 2009.

ALMEIDA, F.O bom negócio da sustentabilidade. Rio de Janeiro: Nova Fronteira, 2002.

ABNT - Associação Brasileira de Normas Técnicas. NBR ISO 14.040. Gestão Ambiental: Avaliação do Ciclo de Vida: princípios e estrutura. Rio de Janeiro: ABNT, 2001. 10pp.

BENITES, L.L.L.; POLO, E.F. A sustentabilidade como ferramenta estratégica empresarial: governança corporativa e aplicação do Triple Bottom Line na Masisa. Revista de Administração da UFSM, v.6, p.195210, 2013.

BRÜSEKE, F.J. O problema do desenvolvimento sustentável. Desenvolvimento e natureza: estudos para uma sociedade sustentável. São Paulo: Cortez, 1995.

CARDOSO, A.C.F. et al. 0 processo de internacionalização e os aspectos socioambientais: o caso Embraer. Revista de Administração da UFSM, v.1, n.1, p.57-70, 2008.

CAVALCANTI, C. Meio ambiente, Celso Furtado e o desenvolvimento como falácia. Ambiente e Sociedade, Campinas: Universidade de Campinas, v.5, n.2, p.73-84, agosto-dezembro 2002.

CONDE, L.C.D. A análise dos impactos socioeconômicos na estruturação do EIA/RIMA: a importância da Abordagem Humanista para a Sustentabilidade. Revista de Administração da UFSM, v.5, p.799-803, 2013.

DA SILVEIRA, A.D.M.; YOSHINAGA, C.E.; BORBA, P.D.R.F. Crítica à teoria dos stakeholders como função-objetivo corporativa. REGE Revista de Gestão, v.12, n.1, p.33-42, 2005.

DAROIT, D.; NASCIMENTO, L.F.Dimensões da inovação sob o paradigma do desenvolvimento sustentável. In: Encontro da Associação Nacional dos Programas de Pós-graduação em Administração, 28, 2004, Curitiba, Anais... Curitiba.

ELKINGTON, J. Partnerships from cannibals with forks: The triple bottom line of 21stcentury business. Environmental Quality Management, v.8, n.1, p.37-51, 1998.

FREEMAN, R. E.Strategic management: a stakeholder approach. Massachusetts: Pitman, 1984.

GIL, A.C. Como elaborar projetos de pesquisa. 5.ed. São Paulo: Atlas, 2010.

HART, S.L.; MILSTEIN, M.B. Criando valor sustentável. RAEexecutivo, v.3, n.2, p.65-79, 2004.

HINZ, R.T.P.; DALLA VALENTINA, L.V.; FRANCO, A.C. Sustentabilidade ambiental das organizações através da produção mais limpa ou pela Avaliação do Ciclo de Vida. Estudos Tecnológicos em Engenharia, v.2, n.2, p.91-98, 2006.

KOTLER, P.; KELLER, K. L. Administração de marketing.12.ed. São Paulo: Pearson Prentice Hall, 750p., 2006. 
KOTLER, P.; KELLER, K. L. Marketing para o século XXI: como criar, conquistar e dominar mercados. 2a .ed. São Paulo, Futura, 1999.

MACIEL, C. et al. Contabilidade ambiental: um estudo exploratório sobre o conhecimento dos profissionais de contabilidade. Rev. Contemporânea Contabilidade, v.7, n.11, p.137-158, 2010. MARCOVITCH, J. Para mudar o futuro: mudanças climáticas, políticas públicas e estratégias empresariais. São Paulo: Edusp, 2006.

MAXWELL, D.; VAN DER VORST, R. Developing sustainable products and services. Journal of Cleaner Production, London, v.11, n.8, p.883-895, 2003.

MELLO, M. M. Desenvolvimento, yrabalho e solidariedade: novos caminhos para a inclusão social. InterfacEHS: Revista de Gestão Integrada em Saúde do Trabalho e Meio Ambiente, v.4, n.3, setdez., 2009, p. 164-181.

NIDUMOLU, R.; PRAHALAD, C.K.; RANGASWAMI, M.R. Why sustainability is now the key driver of innovation. Harvard Business Review, v.87, n.9, p.56-64, 2009.

PORTER, M.E.; LINDE, C.V.D. Green and Competitive: Ending the Stalemate. Harvard Business Review, Cambridge, v.73, n.5, p.120-134, set-oct. 1995a.
PORTER, M.E.; LINDE, C.V.D. Toward a New Conception of the Environment-Competitiveness Relationship. The Journal of Economic Perspectives, Pittsburgh, v.9, n.4, p.97-118, 1995 b.

SANTOS, Adalto de Oliveira etal. Contabilidade ambiental: um estudo sobre sua aplicabilidade em empresas Brasileiras. Revista Contabilidade \& Finanças, v.12, n.27, p.89-99, 2001.

\section{SILVA, G.A; KULAY, L.A. Modelos e ferramentas de gestão ambiental. São Paulo: SENAC, 2006.}

\section{SMERALDI, R.O novo manual de negócios}

sustentáveis. 2.ed. São Paulo: Publifolha, 2009.

VEIGA, J. E; ZATZ, L. Desenvolvimento sustentável, que bicho é esse? Campinas, SP: Autores Associados, 2008.

VIEIRA, S. Como elaborar questionários. São Paulo: Atlas, 2009.

YIN, R. K. Estudo de caso: planejamento e métodos. 4. ed. Porto Alegre: Bookman, 2010. 




\section{PRODUÇ̃̃̃}

Editora Universitária Tiradentes

\section{IMPRESSÃO}

Gráfica Gutemberg

Universidade Tiradentes

\section{TIRAGEM}

150

\section{TIPOGRAFIA}

Signika

Bebas Neue

Arial

PAPEL

Papel Supremo 250g/m2

Miolo

Papel Offset 90g/m2 